\title{
Hatfield Graduate Journal of Public Affairs
}

Volume 2

Issue 1 Hatfield Graduate Journal of Public

Affairs

June 2017

\section{Communities of Concentrated Poverty: A Proposal for Oregon}

Sara A. Chopp

Portland State University

Follow this and additional works at: https://pdxscholar.library.pdx.edu/hgjpa

Part of the Public Affairs, Public Policy and Public Administration Commons Let us know how access to this document benefits you.

\section{Recommended Citation}

Chopp, Sara A. (2017) "Communities of Concentrated Poverty: A Proposal for Oregon," Hatfield Graduate Journal of Public Affairs: Vol. 2: Iss. 1, Article 6.

https://doi.org/10.15760/hgjpa.2017-2.6

This open access Policy Brief is distributed under the terms of the Creative Commons Attribution-NonCommercialShareAlike 4.0 International License (CC BY-NC-SA 4.0). All documents in PDXScholar should meet accessibility standards. If we can make this document more accessible to you, contact our team. 


\title{
Communities of Concentrated Poverty A Proposal for Oregon
}

\author{
Sara Ann Chopp \\ Portland State University
}

This paper is a proposal for how to address poverty in Oregon based on information gathered from interviewing experts in the field and reviewing literature produced by scholars and organizations that address issues related to poverty. The following outlines how we can best address communities of concentrated poverty in Oregon by (1) Addressing communities of concentrated poverty as well as individuals in poverty; (2) Designing efforts that focus on race, equity and social mobility; (3) Defining communities of concentrated poverty using a multidimensional definition based on the dimensions of poverty outlined in The Organisation for Economic Co-operation and Development's 2016 DAC Guidelines; (4) Identifying communities of concentrated poverty using the "High Poverty Hotspots" list from the Oregon Department of Human Services Office of Forecasting, Research, and Analysis and measuring poverty using the Self-Sufficiency Standard developed by Dr. Diana Pearce at the University of Washington and adopted by Elizabeth Morehead, Ph.D., and Sheila Martin, Ph.D., at the Institute of Portland Metropolitan Studies at Portland State University; and (5) Developing Communities of Opportunity (CoO) using the Center for American Progress State Promise Zone Framework. 


\section{INTRODUCTION}

$\mathrm{T}$ HERE ARE INITIATIVES that have a demonstrated return on investment and clear benefits for individuals who live in poverty. However, it is also important to address communities of concentrated poverty because individual poverty is impacted by where people live. The negative effects of poverty are more severe for individuals living in communities of concentrated poverty because the effects are concentrated in one area. Consequently, these negative effects spill over and impact all members of the community, regardless of socioeconomic status.

Sara Chopp, a PhD student at Portland State University, interviewed experts to identify promising practices for addressing communities of concentrated poverty in Oregon. This proposal is based on what experts in the field view as the greatest barriers and the greatest opportunities to addressing issues of poverty.

According to experts, the greatest barriers to addressing issues of poverty include structural inequality, structural racism, color-blind public policy, lack of culturally responsive systems, fragmentation in social services, lack of data and evaluation capacity, and inability to shift how we communicate about poverty from viewing it as an identity to treating it as an experience. Whitney Grubbs, Project Director at Foundations for a Better Oregon, commented in a 2015 interview, "Racism and equity need to be addressed or we'll never get there."1

According to experts, the greatest opportunities for addressing poverty are multi-level, multi-jurisdictional, cross-sector collaborative approaches. We can pursue these opportunities using the collective impact framework developed by John Kania, Managing Director at FSG, and Mark Kramer, Senior Fellow at Harvard University's Kennedy School and co-founder of FSG. ${ }^{2}$ According to FSG, "collective impact is a powerful new approach to cross-sector collaboration that is achieving measurable effects on major social issues." 3 FSG identifies the following five conditions associated with successful collective impact initiatives "that together produce alignment and lead to powerful results:" (1) A common agenda, (2) Shared measurement systems, (3) Mutually reinforcing activities, (4) Continuous communication, (5) Backbone support organizations and to that list, we would add (6) A racial equity lens. ${ }^{4}$ 
Experts suggest that initiatives should be place-based and communitydriven with holistic and integrative approaches that aim to address the drivers of poverty. Communities of concentrated poverty should be provided with the resources necessary to feel empowered as owners of their solutions. These communities are filled with untapped human resources, talents, and potential as well as unused social capital. If provided with opportunities, residents within these communities can develop or increase the leadership and capacity required to transform their communities. There are many examples of such communities.

\section{Addressing Communities of Concentrated Poverty as Well as Individuals in Poverty}

One must understand the nature of poverty and all of its complexities in order to design solutions that will lead toward its eradication. There are negative outcomes from poverty that effect individuals living in poverty, and these effects are exacerbated by living in communities of concentrated poverty. People living in these areas suffer from a lack of opportunities in terms of economic and job development, housing, education, and health care. In these communities there is a lack of infrastructure and transportation necessary for development and connection, as well as a lack of culturally responsive services. This has profound effects on these communities, such as high concentration of child maltreatment, domestic violence and substance abuse. These issues endure across generations and produce multi-generational trauma that impacts everyone in these communities regardless of socioeconomic status.

According to Melissa Boteach, Vice President of the Poverty to Prosperity Program at the Center for American Progress (CAP), high levels of crime, poor schools, and health disparities are apparent for the whole community in areas where 30 to 40 percent of individuals fall below the Federal Poverty Line (FPL). ${ }^{5}$ Ian Galloway, Senior Research Associate of Community Development at the Federal Reserve Bank of San Francisco commented in a 2015 interview, "If you can tackle 15 percent of neighborhoods then you could solve 80 percent of the problem." 6

Children and families are impacted by living in communities of concentrated poverty. CAP finds that people who live in "neighborhoods of concentrated disadvantage" experience the following: Impaired children's cognitive development and school performance, negative impact on adult 
employment and earnings and increased mental and physical health problems (Ross and Boteach 2014, p.4). ${ }^{7}$

CAP defines "living in neighborhoods of concentrated disadvantage" in terms of (1) Racial segregation, (2) Rates of unemployment, (3) The share of single-parent families and (4) Exposure to neighborhood violence. ${ }^{8}$

Communities of color are disproportionately affected. In addition, CAP points out that these issues disproportionately affect communities of color, particularly African Americans, American Indians and Alaskan Natives, and Latinos because these groups are more likely than whites to live in areas of concentrated poverty. ${ }^{9}$

\section{Designing Efforts That Focus on Race, Equity, and Social Mobility}

It is important to understand what factors are correlated with the emergence and persistence of communities of concentrated disadvantage in order to develop appropriate policy interventions for addressing povertyrelated issues in such communities. Advantages present in a community can be determined by measuring the level of social mobility experienced by people living there. According to Steven Aldridge in "Social Mobility: A Discussion Paper," social mobility describes "the movement or opportunities for movement between different social groups, and the advantages and disadvantages that go with this in terms of income, security of employment, opportunities for advancement etc". ${ }^{10}$

CAP draws on research findings by Raj Chetty, Nathaniel Hendren, Patrick Kline and Emmanuel Saez in "Where is the Land of Opportunity? The Geography of Intergenerational Mobility in the United States," that reveal the following community characteristics as high social mobility correlates: (1) Less segregation, (2) Less income inequality, (3) Better schools, (4) Greater social capital and (5) More stable families. ${ }^{11}$ Where the high correlates are present, you have high social mobility/advantage. Where the correlates are not present, you have low social mobility/disadvantage.

Communities of concentrated poverty are the least advantaged, and communities of color are disproportionately represented in these areas. Therefore, communities of color disproportionately experience inequity in access to opportunities and, consequently, greater disparities in educational 
and health outcomes. This is why it is important to design efforts that focus on race, equity and indicators of social mobility. Mayra Arreola, Director of Community Collaborations and Investments at United Way, commented in a 2015 interview, "We use a strong racial equity lens. Every strategy is deeply rooted in foundational belief of how do we make sure that communities of color have equal access and opportunities as everyone else in the region." 12

Targeting social mobility correlates to improved access to opportunities in terms of healthcare, education, economic and job development, and housing and transportation. Such access can improve living conditions and individuals' wellbeing throughout communities of concentrated poverty, because everyone living in these areas, regardless of socioeconomic status, benefits from better conditions created there. When individuals living in communities of concentrated poverty are able to enhance their situations as a result of improved conditions, they are better able to contribute to economic growth in their communities. When communities of concentrated poverty are able to boost their resources, they require less support from outside sources and they are better able to contribute to the greater economies, thus ultimately enhancing prosperity for all.

\section{Communities of Concentrated Poverty: A Multidimensional Definition}

We need to define communities of concentrated poverty in order to know where to focus resources to help communities identify challenges, develop outcomes and create a plan for developing target areas, such as healthcare, education, economic and job development, and housing and transportation.

Experts describe communities of concentrated poverty as neighborhoods where poverty is perpetuated and there are high levels of alienation, disengagement, hopelessness, and disconnection. Experts describe these areas as hot spots for disparities in which communities of color are disproportionately represented. Bill Johnson, Owner of Sage Farms in Malheur County, commented in a 2015 interview, "Hope matters. You have to have hope for what the future holds for you personally and for the community. If you lose faith for the community, you leave the community." 13

The Organisation for Economic Co-operation and Development's (OECD) has constructed a broad, multidimensional definition of poverty that identifies the following capabilities as the most important for addressing 
poverty that includes: (1) Economic capabilities: The ability to earn income and to have and consume assets is a key to food security, material wellbeing, and social status. (2) Human capabilities: Health, education, nutrition, clean water, and shelter are core elements of well-being and crucial for improving livelihoods, (3) Political capabilities: Human rights and having a voice and influence over public policies and political priorities are important for addressing poverty (4) Socio-cultural capabilities: The ability to participate as a valued member of a community is important for increasing resources and improving wellbeing and (5) Protective capabilities: Being enabled to withstand economic and external shock is important for addressing poverty. ${ }^{14}$

According to the Development Assistance Committee Guidelines, these capabilities are relevant across contexts and individuals and should therefore be included in any definition of poverty. ${ }^{15}$ This definition has been used to describe the poverty of individuals, but it can also be used to describe communities of concentrated poverty when the unique characteristics of a place and its people are taken into account. For example, although the experience of living in poverty in rural areas may differ from the experience of living in poverty in urban areas, the OECD dimensions could serve as descriptors for both. Bill Johnson commented in a 2015 interview, "There are different versions of rural. If you have 30,000 people you have education opportunities and industries. This changes dramatically when you go to less populated areas." 16

\section{Measuring Communities of Concentrated Poverty: The Self-Sufficiency Standard}

OECD recognizes that defining poverty with respect to the poverty dimensions is complicated, and poverty assessments may be expensive to conduct. ${ }^{17}$ Therefore, the way poverty is measured must be distinct from how it is defined. Currently, the federal poverty line (FPL) is the most widely used measure for identifying communities of concentrated poverty. Communities of poverty are those where 20-40 percent of individuals fall below the FPL. However, experts agree that the FPL is an inadequate and antiquated measure of poverty because it is based on methodology and living conditions that were relevant in the 1960s. Consequently, the FPL does not capture a realistic percentage of individuals living in poverty and is, therefore, not a good measure for identifying communities of concentrated poverty. An alternative measure is needed for accurately measuring the percentage of individuals in poverty in order to better locate communities of concentrated poverty. 
Dr. Liza Morehead, Director of Research at the Institute of Portland Metropolitan Studies (IMS), and Dr. Sheila Martin, Director of IMS and the Population Research Center use the Self-Sufficiency Standard (the Standard), which was developed by Dr. Diana Pearce at the University of Washington, as an alternative to the FPL in order to measure poverty in Oregon. ${ }^{18}$ The Standard is more accurate than the FPL because it does the following: (1) Accounts for housing, childcare, healthcare and transportation costs, (2) Adjusts for geography and ages of children, (3) Includes the effect of federal, state and local taxes and tax credits on household income, (4) Establishes an up-to-date Standard, (5) includes the Public Use Micro Sample (PUMS) file of the 2010-2012 American Community Survey (ACS) to determine the percentage of households in Oregon that meet the Standard, and (6) Characterizes poverty in terms of race/ethnicity, household type, education, employment patterns, and occupation. ${ }^{19}$

It is difficult to break Oregon down into sub-counties in order to identify geographic areas where there is a high percentage of poverty as defined by the Standard because some counties are sparsely populated. However, we can use the "High Poverty Hotspots" list, produced by the Oregon Department of Human Services (DHS), to identify communities of concentrated poverty within each county based on where 20 percent of individuals fall below the FPL. ${ }^{20}$ The "High Poverty Hotspots" list can be used to identify communities of concentrated poverty and the Standard can be used to measure poverty in these areas. Using these tools in combination would show a more accurate poverty rate for these communities. This approach is important because, if the poverty rate in these communities is greater based on the Standard than based on the FPL, more communities of concentrated poverty could become targets for funding.

\section{State Promise Zones: A Proposal from the Center for American Progress}

The Center for American Progress (CAP) proposes that states can address communities of concentrated poverty by establishing these communities as "State Promise Zones" (SPZ). ${ }^{21}$ According to the U.S. Department of Housing and Urban Development (HUD), the SPZ framework is based on the federal Promise Zone bi-partisan initiative that "designate[d] a number of high-poverty urban, rural and tribal communities as Promise Zones, where the federal government...partner[ed] with and invest[ed] in communities to...create jobs, leverage private investment, increase economic activity, 
expand educational opportunities, and reduce violent crime" (HUD 2016, par. 2). ${ }^{22}$ The federal government provided Promise Zones with the following: (1) Support from AmeriCorp VISTA members, (2) A federal liaison for navigating federal programs, (3) Priority access to federal grant programs, (4) Technical assistance from federal agencies and (5) Tax incentives (pending) (HUD 2016, par. 3). ${ }^{23}$

In a 2015 interview, Melissa Boteach, Vice President of CAP's Poverty to Prosperity Program, suggested that the SPZ framework can be used at the state level to address communities of concentrated poverty. ${ }^{24}$ Once these communities are identified, they can be considered priority areas for community-based development, and state leaders can mobilize resources and knowledge in a way that concentrates efforts in these areas.

\section{Funding the Promise Zones}

States can fund promise zones by leveraging existing resources. CAP suggests that to create income supports in communities of concentrated poverty, states should streamline access to critical work and income supports. ${ }^{25}$ Suggestions from CAP include: (1) Expanding the state Earned Income Tax Credit and improving tax-time outreach in SPZ areas in order to increase use of the credit and to enhance income supports in these communities; (2) Giving priority access to state resources and federal funding streams (i.e. the Social Services Block Grant and the Community Development Block Grant) to communities of concentrated poverty; and (3) Using AmeriCorps grant funding, and dedicating staff as points of contact to provide added capacity and to help people in the SPZ areas navigate state resources. ${ }^{26}$ (See Appendix A)

\section{ELIGIBILITY}

According to CAP, "Promise Zone applicants are required to outline the outcomes they want to achieve, describe their capacity to do so and the roles of their partners to demonstrate past successes, and commit to using data to drive outcomes." 27

In order to be eligible, CAP proposes that applicants meet the following standards: (1) Demonstrated need with respect to overall poverty indicators; (2) Specific geographic area that captures one or more census tracts; (3) Designated population size that is specific to rural or urban guidelines to 
ensure impact for a significant portion of the population; (4) Qualifying lead applicant that has capacity and legitimacy for steering collaborative networks; and (5) Support from local leadership for the effort. ${ }^{28}$

CAP advises that State Promise Zone applications should focus on: (1) Attracting private investment to create jobs and spur economic development; (2) Improving the education-workforce pipeline; (3) Creating safe and healthy communities; and (4) Repairing and preserving housing and infrastructure. ${ }^{29}$

According to CAP, priority should be given to community collaboratives that are between the "Plan" and "Align \& Improve" stages in the spectrum of "community collaborative life stages" described in (see Figure 1). Applicants should have a lead support organization that works to create and manage collective impact by coordinating participating organizations.

\section{EvALUATION}

Applicants should be evaluated based on strength of their initiative with respect to the capacity of local leaders and the level of commitment among actors, which can be demonstrated by identifying a set of outcomes for revitalizing the community as well as a strategy for reaching those outcomes in addition to describing how data will be used to redirect resources toward what works.

\section{Communities of Opportunity: A Proposal for Oregon}

The SPZ framework can be used to develop "Communities of Opportunity (CoO)" in Oregon. Areas that already have successful initiatives on the ground should be given priority. Therefore, once the communities of concentrated poverty in Oregon are identified, these communities should be provided the opportunity to apply for CoO status based on the SPZ criteria. Consideration should be given to community initiatives that are building on existing organizational initiatives such as the Regional Achievement Collaboratives, Early Learning Hubs, STEM Hubs, Workforce Investment Boards, and Regional Solutions Teams.

In addition to meeting the eligibility standards and satisfying the application guidelines suggested by CAP, communities wishing to be considered a $\mathrm{CoO}$ would need to: 


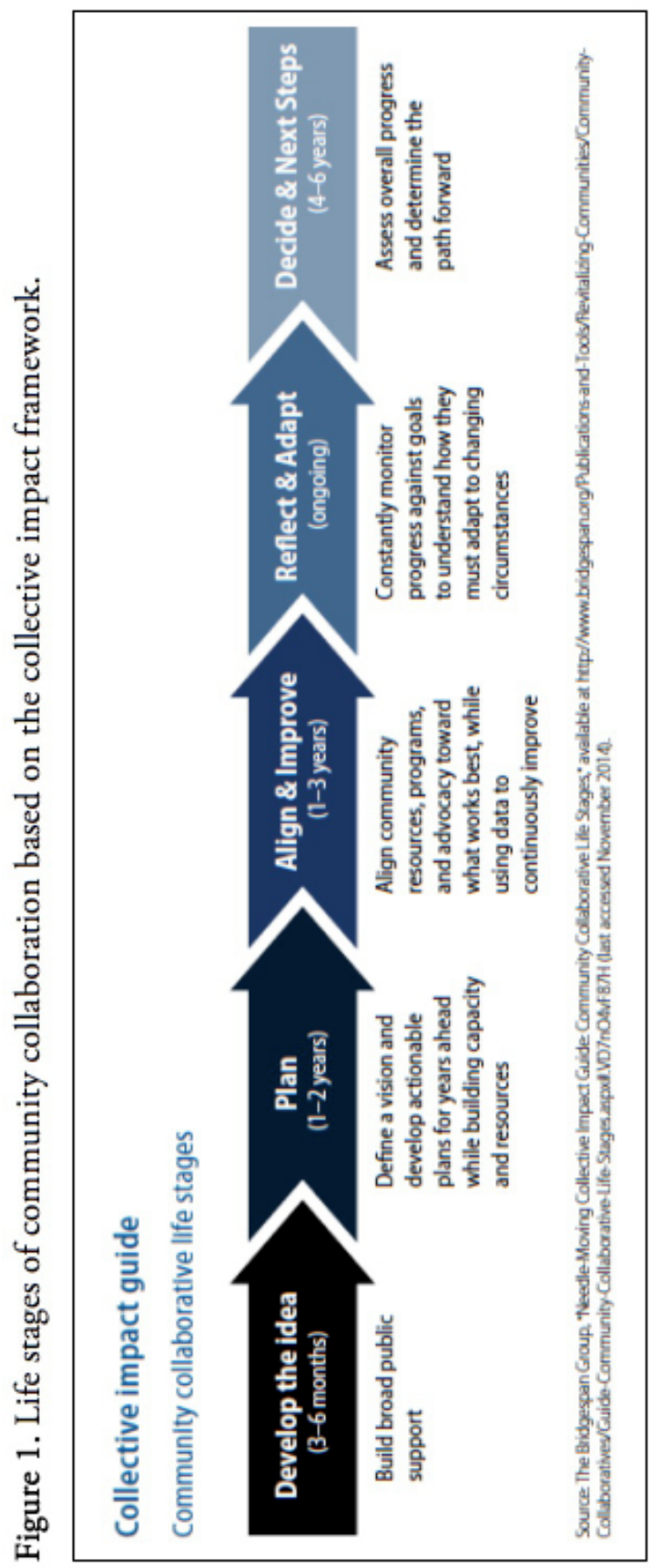




\section{Address communities of concentrated poverty as well as individual poverty}

Demonstrate a commitment to addressing poverty at the community level, as well as the individual level. This would mean targeting community needs, not just individuals, for outreach efforts in addition to addressing structural and systemic issues.

\section{Design efforts that focus on race, equity, and social mobility}

Demonstrate commitment to focusing efforts on social mobility correlates and racial equity in order to create more advantages and opportunities in communities of concentrated poverty. This means using a racial equity lens as well as prioritizing efforts for reducing segregation and income inequality, and producing better schools, greater social capital, and stable families. These actions could help communities break cycles of multi-generational poverty, particularly in communities of color.

\section{Use a multidimensional definition to define poverty in the community}

Using the OECD dimensions will allow communities to identify problems, generate solutions, and track progress more effectively. In a 2015 interview, Lena Etuk, a Family Development Specialist and Social Demographer at Oregon State University, described how she uses a similar approach to help communities work towards prosperity. ${ }^{30}$ Etuk supports communities in defining vitality from a local perspective according to their own values, norms, and aspirations then develops indicators of that vital future. ${ }^{31}$ These indicators are related to social, economic, and environmental outcomes as well as capacity. The communities use these indicators to set targets or goals for each. This goal-setting is followed by an assessment of community vitality which is then used by community leaders to identify priorities and strategies to reach the goals. This approach could serve as a model for how communities could use the OECD dimensions to set goals. 


\section{measure poverty in the community}

The FPL is how poverty hotspots are currently defined, but the SelfSufficiency Standard provides a more accurate measure of poverty in these areas. By referring to the Self-Sufficiency Standards and the Median Household Incomes for Oregon Counties chart to identify the number of households that live in poverty in the community, communities of concentrated poverty could leverage more funding for improving capabilities and increasing social mobility.

At the center of the effort, we need local, state and federal agencies to collaborate with private and nonprofit organizations to integrate funding streams, align operating systems, and help increase upward social mobility. These efforts should support community strategies and projects that use the collective impact framework, which includes having a common agenda, shared measurement, mutually-reinforcing activities, continuous communication, and a backbone organization. Community strategies and projects should also focus on social mobility, race, and equity. These combined efforts should be informed by and inform the ways in which poverty is measured and defined with respect to the Self-Sufficiency Standard and the unique characteristics of the communities, respectively. Using this approach could enhance the capabilities of communities of concentrated poverty and the individuals who live there, which could ultimately lead to the expansion of opportunities in these communities. See Figure 2 for a description of this process.

\section{Conclusion}

Poverty is a complex condition and many barriers limit efforts to eradicate it. However, many promising opportunities for addressing poverty could produce lasting change. We can better understand the complex nature of poverty by defining communities of concentrated poverty using a multidimensional definition, and we can better gauge human need by measuring poverty using the Self-Sufficiency Standard rather than the Federal Poverty Level alone. By using these tools, we can better support communities as well as individuals in need. We can start breaking barriers by designing efforts that focus on race, equity and social mobility. And we can produce greater collective impact by developing Communities of Opportunity where cross-sector collaboration can take place and the community can lead the way towards solutions that make a lasting difference for all. 


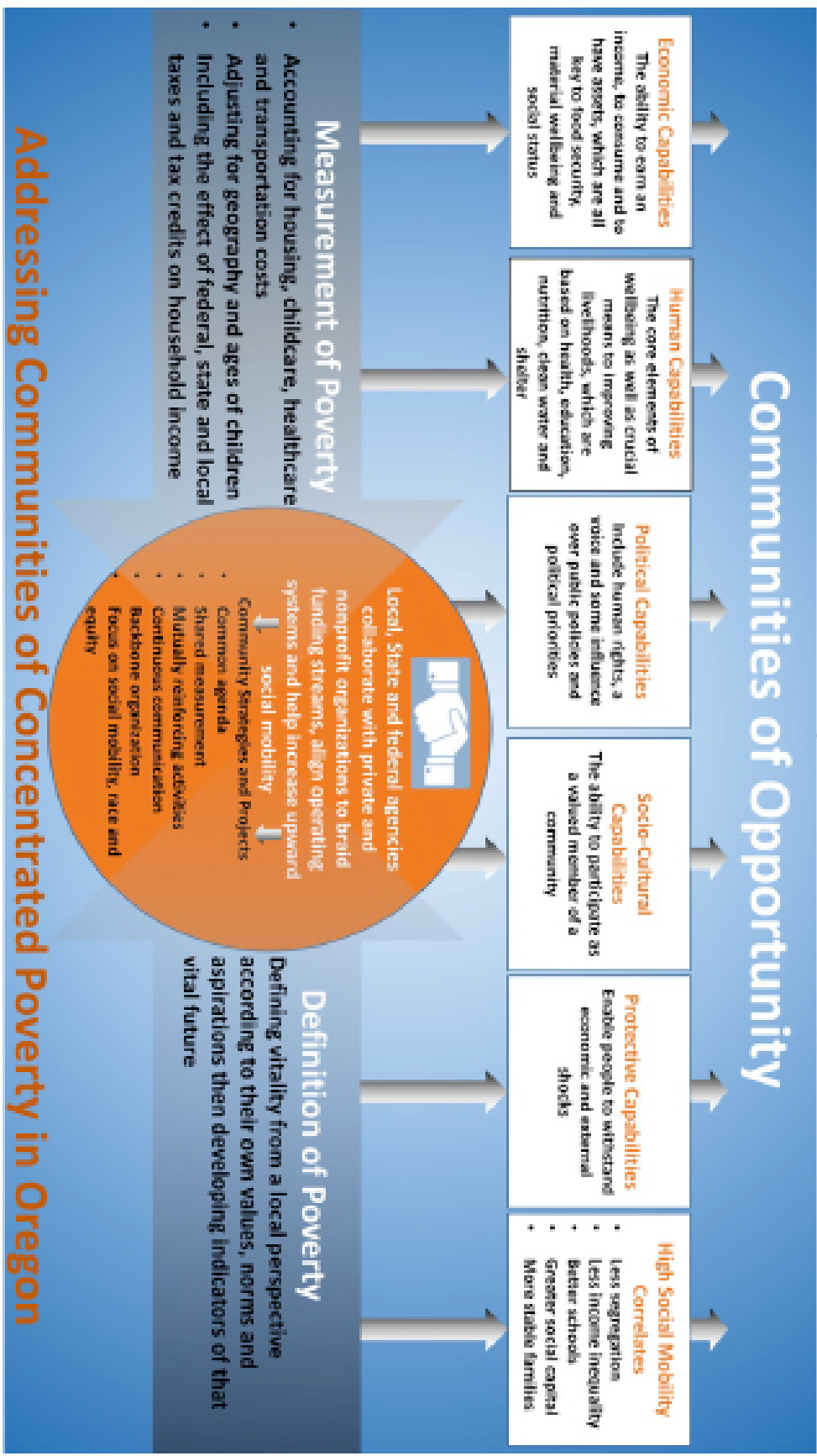

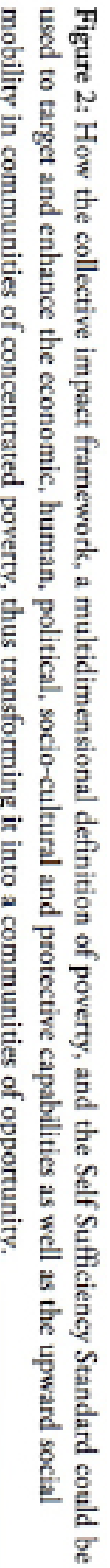


Michael Heyn, United Nations Official (Retired), commented in a 2015 interview, "[By] giving [the] poor a real voice and [using this as] the first way of defining what needs to be done... and how it should be done, you get really good ideas that are ground-based and coming from reality [and] at the same time you're...building confidence of people to engage in the process." ${ }^{2}$

\section{Notes}

${ }^{1}$ Boteach, Melissa. Interview by Sara Chopp. Personal Interview. Phone, November 3, 2015.

2 “The DAC Guidelines: Poverty Reduction," accessed April 26, 2016, http://www.oecd.org/dac/ povertyreduction/2672735.pdf.

${ }^{3}$ High Poverty Hotspots - 2015 County Table, accessed April 26, 2016, http://webcache. googleusercontent.com/search?q=cache:_r2iWq7xGgEJ:www.oregon.gov/DHS/ BUSINESSSERVICES/OFRA/ofradocuments/High\%2520Poverty\%2520Hotspots\%2520$\% 25202015 \% 2520$ County $\% 2520$ Table.docx $\& \mathrm{~cd}=3 \& \mathrm{hl}=\mathrm{en} \& \mathrm{ct}=\mathrm{clnk} \& \mathrm{gl}=\mathrm{us}$

4 "Where the Ends Don't Meet in 2014: Measuring Poverty and Self-Sufficiency among Oregon's Families," last modified June, 2015, http://www.pdx.edu/ims/sites/www.pdx.edu.ims/files/Where_ the_Ends_Dont_Meet_in_2014.pdf

5 “A Framework for State-Level Promise Zones," last revised December 2014, www.americanprogress. org/wp-content/uploads/2014/12/Ross-PromiseZone-report2.pdf.

${ }^{6}$ Grubbs, Whitney. Interview by Sara Chopp. Personal Interview. Portland, Oregon, November 5 , 2015.

7 “Collective Impact." accessed April 26, 2016, http://www.fsg.org/publications/collectiveimpact\#download-area.

8 “Collective Impact." accessed April 26, 2016, http://www.fsg.org/publications/collectiveimpact\#download-area.

9 “Collective Impact." accessed April 26, 2016, http://www.fsg.org/publications/collectiveimpact\#download-area.

${ }^{10}$ Boteach, Melissa. Interview by Sara Chopp. Personal Interview. Phone, November 3, 2015.

${ }^{11}$ Galloway, Ian. Interview by Sara Chopp. Personal Interview. Portland, Oregon, December 15, 2015.

12 "A Framework for State-Level Promise Zones," last revised December 2014, www.americanprogress. org/wp-content/uploads/2014/12/Ross-PromiseZone-report2.pdf.

13 "A Framework for State-Level Promise Zones," last revised December 2014, www.americanprogress. org/wp-content/uploads/2014/12/Ross-PromiseZone-report2.pdf.

14 “A Framework for State-Level Promise Zones," last revised December 2014, www.americanprogress. org/wp-content/uploads/2014/12/Ross-PromiseZone-report2.pdf.

${ }^{15}$ Stephen Aldridge, "Social Mobility: A Discussion Paper." (paper presented in the Seminar held by the Performance and Innovation Unit, London, England, UK, March 20, 2001), http:// kumlai.free.fr/RESEARCH/THESE/TEXTE/MOBILITY/mobility\%20salariale/SOCIAL\%20 


\section{MOBILITY.pdf,}

${ }^{16}$ Raj Chetty, Nathaniel Hendren, Patrick Kline and Emmanuel Saez, "Where is the Land of Opportunity? The Geography of Intergenerational Mobility in the United States," The Quarterly Journal of Economics 129(4) (2014): 1553-1623, doi: 10.3386/w19843.

${ }^{17}$ Arreola, Mayra. Interview by Sara Chopp. Personal interview. Phone, December 9, 2015.

${ }^{18}$ Johnson, Bill. Interview by Sara Chopp. Personal Interview. Phone, October 30, 2015.

19 "The DAC Guidelines: Poverty Reduction," accessed April 26, 2016, http://www.oecd.org/dac/ povertyreduction/2672735.pdf.

20 "The DAC Guidelines: Poverty Reduction," accessed April 26, 2016, http://www.oecd.org/dac/ povertyreduction/2672735.pdf.

${ }^{21}$ Johnson, Bill. Interview by Sara Chopp. Personal Interview. Phone, October 30, 2015.

22 “The DAC Guidelines: Poverty Reduction,” accessed April 26, 2016, http://www.oecd.org/dac/ povertyreduction/2672735.pdf.

23 "Where the Ends Don't Meet in 2014: Measuring Poverty and Self-Sufficiency among Oregon's Families," last modified June, 2015, http://www.pdx.edu/ims/sites/www.pdx.edu.ims/files/Where_ the_Ends_Dont_Meet_in_2014.pdf

24 "Where the Ends Don't Meet in 2014: Measuring Poverty and Self-Sufficiency among Oregon's Families," last modified June, 2015, http://www.pdx.edu/ims/sites/www.pdx.edu.ims/files/Where_ the_Ends_Dont_Meet_in_2014.pdf

${ }^{25}$ High Poverty Hotspots - 2015 County Table, accessed April 26, 2016, http://webcache. googleusercontent.com/search?q=cache:_r2iWq7xGgEJ:www.oregon.gov/DHS/

BUSINESS-SERVICES/OFRA/ofradocuments/High\%2520Poverty\%2520Hotspots\%2520$\% 25202015 \% 2520$ County $\% 2520$ Table.docx $+\& \mathrm{~cd}=3 \& \mathrm{hl}=\mathrm{en} \& \mathrm{ct}=\mathrm{clnk} \& \mathrm{gl}=\mathrm{us}$

26 “A Framework for State-Level Promise Zones," last revised December 2014, www.americanprogress. org/wp-content/uploads/2014/12/Ross-PromiseZone-report2.pdf.

27 “Promise Zones Overview," accessed April 26, 2016, https://www.hudexchange.info/programs/ promise-zones/promise-zones-overview/.

28 "Promise Zones Overview," accessed April 26, 2016, https://www.hudexchange.info/programs/ promise-zones/promise-zones-overview/.

${ }^{29}$ Boteach, Melissa. Interview by Sara Chopp. Personal Interview. Phone, November 3, 2015.

30 "A Framework for State-Level Promise Zones," last revised December 2014, www.americanprogress. org/wp-content/uploads/2014/12/Ross-PromiseZone-report2.pdf.

31 “A Framework for State-Level Promise Zones," last revised December 2014, www.americanprogress. org/wp-content/uploads/2014/12/Ross-PromiseZone-report2.pdf.

32 "A Framework for State-Level Promise Zones," last revised December 2014, www.americanprogress. org/wp-content/uploads/2014/12/Ross-PromiseZone-report2.pdf.

33 "A Framework for State-Level Promise Zones," last revised December 2014, www.americanprogress. org/wp-content/uploads/2014/12/Ross-PromiseZone-report2.pdf.

34 “A Framework for State-Level Promise Zones," last revised December 2014, www.americanprogress. org/wp-content/uploads/2014/12/Ross-PromiseZone-report2.pdf.

${ }^{35}$ Etuk, Lena. Interview by Sara Chopp. Personal Interview. Phone, November 3, 2015. 
${ }^{36}$ Etuk, Lena. Interview by Sara Chopp. Personal Interview. Phone, November 3, 2015.

${ }^{37}$ Heyn, Michael. Interview by Sara Chopp. Personal Interview. Portland, Oregon, November 19, 2015.

38 "A Framework for State-Level Promise Zones," last revised December 2014, www.americanprogress. org/wp-content/uploads/2014/12/Ross-PromiseZone-report2.pdf.

39 "A Framework for State-Level Promise Zones," last revised December 2014, www.americanprogress. org/wp-content/uploads/2014/12/Ross-PromiseZone-report2.pdf.

40 "A Framework for State-Level Promise Zones," last revised December 2014, www.americanprogress. org/wp-content/uploads/2014/12/Ross-PromiseZone-report2.pdf.

41 “A Framework for State-Level Promise Zones," last revised December 2014, www.americanprogress. org/wp-content/uploads/2014/12/Ross-PromiseZone-report2.pdf.

42 "A Framework for State-Level Promise Zones," last revised December 2014, www.americanprogress. org/wp-content/uploads/2014/12/Ross-PromiseZone-report2.pdf.

\section{REFERENCES}

“A Framework for State-Level Promise Zones," last revised December 2014, www.americanprogress. org/wp-content/uploads/2014/12/Ross-PromiseZone-report2.pdf.

Arreola, Mayra. Interview by Sara Chopp. Personal interview. Phone, December 9, 2015.

Barros, Rocque. Interview by Sara Chopp. Personal interview. Phone, December 30, 2015.

Beegle, Donna. Interview by Sara Chopp. Personal Interview. Portland, Oregon, December 17, 2015.

Boteach, Melissa. Interview by Sara Chopp. Personal Interview. Phone, November 3, 2015.

"Collective Impact." accessed April 26, 2016, http://www.fsg.org/publications/collectiveimpact\#download-area.

Kais Al-momani, "Social Mobility and Community Participation amongst Jordanians in Australia." (paper presented in the Annual Conference of the Royal Economic Society Conference held by the University of Surrey, Guilford, Surrey, UK, March 29-31, 2010), http://www.surrey.ac.uk/cronem/ files/conf2010papers/Al-momani.pdf

Etuk, Lena. Interview by Sara Chopp. Personal Interview. Phone, November 3, 2015.

Galloway, Ian. Interview by Sara Chopp. Personal Interview. Portland, Oregon, December 15, 2015.

Green, Beth. Interview by Sara Chopp. Personal Interview. Portland, Oregon, December 15, 2015.

Grubbs, Whitney. Interview by Sara Chopp. Personal Interview. Portland, Oregon, November 5, 2015.

Heyn, Michael. Interview by Sara Chopp. Personal Interview. Portland, Oregon, November 19, 2015.

High Poverty Hotspots - 2015 County Table, accessed April 26, 2016, http://webcache. 
googleusercontent.com/search?q=cache:_r2iWq7xGgEJ:www.oregon.gov/DHS/

BUSINESS-SERVICES/OFRA/ofradocuments/High\%2520Poverty\%2520Hotspots\%2520-

$\% 25202015 \% 2520$ County $\% 2520$ Table.docx $\& \mathrm{~cd}=3 \& \mathrm{hl}=\mathrm{en} \& \mathrm{ct}=\mathrm{clnk} \& \mathrm{gl}=\mathrm{us}$

Johnson, Bill. Interview by Sara Chopp. Personal Interview. Phone, October 30, 2015.

"Promise Zones Overview," accessed April 26, 2016, https://www.hudexchange.info/programs promise-zones/promise-zones-overview/.

Raj Chetty, Nathaniel Hendren, Patrick Kline and Emmanuel Saez, "Where is the Land of Opportunity? The Geography of Intergenerational Mobility in the United States," The Quarterly Journal of Economics 129(4) (2014): 1553-1623, doi: 10.3386/w19843.

Stephen Aldridge, "Social Mobility: A Discussion Paper." (paper presented in the Seminar held by the Performance and Innovation Unit, London, England, UK, March 20, 2001), http://kumlai.free. fr/RESEARCH/THESE/TEXTE/MOBILITY/mobility\%20salariale/SOCIAL\%20MOBILITY. pdf.

Straw, Nancy. Interview by Sara Chopp. Personal Interview. Phone, December 30, 2015.

“The DAC Guidelines: Poverty Reduction," accessed April 26, 2016, http://www.oecd.org/dac/ povertyreduction/2672735.pdf.

Tromba, Peter. Interview by Sara Chopp. Personal Interview. Phone, November 4, 2015.

"Where the Ends Don't Meet in 2014: Measuring Poverty and Self-Sufficiency among Oregon's Families," last modified June, 2015, http://www.pdx.edu/ims/sites/www.pdx.edu.ims/files/Where_ the_Ends_Dont_Meet_in_2014.pdf.

Wolf, Greg. Interview by Sara Chopp. Personal Interview. Phone, November 9, 2015.

\section{Appendix A}

\section{More Advice from the Center for American Progress}

To create income supports, states should: Reduce states' administrative costs by building upon lessons learned from demonstrations such as the Work Support Strategies initiative (Medicaid/CHIP/SNAP/TANF) (Ross and Boteach 2014, p.27). ${ }^{33}$

To attract private investment and create jobs, states should: Require Promise Zones applicants to map out their community investment infrastructure (Ross and Boteach 2014, p.22). ${ }^{34}$

To create an education-workforce pipeline, states should: (1) Ensure state Promise Zones applicants align their education and workforce development 
systems (WIOA; SIGs); (2) Target smaller educational funding streams to Promise Zones (Prioritize for after school programs; 21st CCLC); (3) Outline expectations for how state colleges and universities should participate in the Promise Zones initiatives; (4) Support workforce development efforts that align with employer needs and increase access to jobs; (5) Prioritize for funding for public school and workforce development services (WIOA; creating opportunity for high school students to get technical education); (6) Establish subsidized jobs in Promise Zones to help families and the economy (TANF); (7) Create city-state resource hubs to help screen residents for benefits eligibility and connect them with the benefits they qualify for but are not receiving; and (8) Create financial empowerment centers to help residents build personal assets (Life Prosperity Accounts; flexible cash assistance) (Ross and Boteach 2014, p.23-25). ${ }^{35}$

To create safe and healthy communities, states should: (1) Require localities to develop a plan for conducting a community health needs assessment, or CHNA (Affordable Care Act; Navigator grant awards; Medicaid; CHIP); (2) Require localities to prioritize resilience measures in the community development efforts; (3) Support efforts that deter crime (JAG); and (4) Enact reforms around the use of criminal records (Ban the Box) (Ross and Boteach 2014, p.28-29). ${ }^{36}$

To develop housing and infrastructure, states should: (1) Consider policies to enable and promote the rehabilitation of affordable housing (LIHTC; CDBG; Pay for Success); (2) Review and update regulatory policies to reduce barriers for development (direct rent subsidies; LIHTC; CDBG; Pay for Success); (3) Protect households from displacement (CDBG; Pay for Success); (4) Support greater access to transportation throughout the Promise Zones initiative (CDBG; Pay for Success); and (5) Ensure a greater connection between transportation and housing development (CDBG; Pay for Success). ${ }^{37}$

\section{ACKNOWLEDGEMENTS}

The report benefited from the input and editing of two Portland State University, Public Affairs and Policy PhD students, Sara Friedman and Michael Figueredo, as well as Melissa Boteach, Vice President, Poverty to Prosperity Program, Center for American Progress and Beverly Stein, 
Senior Fellow at the National Policy Consensus Center. Thank you to Cat McGinnis, Development Editor, College of Urban \& Public Affairs, Portland State University, for editing and formatting this report. A special thank you to all of the experts who contributed their time and insights to this report. 